\title{
NICOTINE SELF-ADMINISTRATION IN MONKEYS*
}

\author{
G. A. Deneau and Reizo Inoki \\ Department of Pharmacology \\ The University of Michigan, Ann Arbor, Mich.
}

\section{Introduction}

There is little doubt that some substance in tobacco smoke or some aspect of the act of smoking leads to habituation in many people. The experiments to be described were conducted in an effort to determine whether a similar type of habituation could be demonstrated in animals, and whether nicotine might be the substance involved.

\section{Methods}

Rhesus monkeys (Macaca mulatta), ranging in weight from 3 to $4.5 \mathrm{~kg}$ were employed in this study. The animals had no history of having received any drugs other than antibiotics in the laboratory. The animals were prepared for the intravenous self-administration experiments according to the procedure of Yanagita, et al. (1965).

In brief, the monkeys were permitted to have relative freedom of movement in a cage approximately one cubic yard in size. To accomplish this, the monkeys were placed in a light, tubular stainless steel harness which was connected, in turn, to a flexible tubular restraining arm, one end of which was anchored to the cage wall. This arrangement permitted the monkey to move within the confines of the cage freely in all respects except that horizontal rotation was restricted to 300 degrees. The monkeys became accustomed to the harness and the limitations of movement within a matter of a few days. At this time, a permanently indwelling catheter was implanted via the external jugular vein into the right atrium. The catheter was led subcutaneously to a point between the shoulder blades where it emerged through the skin, was led through the tubular restraining arm, and attached to a mechanical injector which was mounted on the outside of the cage. The restriction of rotation imposed by the restraining arm prevented fouling of the catheter by repeated circling movement of the monkey.

The mechanical injector consisted of a motor-driven syringe which could be activated either by an electrical timer or by the monkey if it pressed an appropriate lever.

After the monkey had recovered from the surgical procedure, and it was determined that the catheter was patent, the lever was placed in a panel in the wall. All monkeys will, out of curiosity, play with any new object which enters their environment and, thereby, activate the injector by pressing the lever. Solutions of nicotine base, dissolved in saline, were delivered to the monkeys

*Supported by a grant from the AMA Committee for Research on Tobacco and Health, and USPHS Grant No. MY 5320. 
when they pressed the lever out of curiosity. It was assumed that if the effects of the nicotine injection were rewarding, the monkeys would associate lever pressing with drug effect and would continue to press the lever.

If monkeys did not continue to self-administer nicotine at a given dose level, the drug was injected automatically every hour for several weeks, or until such time as the monkeys began to take supplementary injections by pressing the lever between the scheduled hourly intervals. When it was apparent that the monkey was not going to self-administer the drug at a particular dose, the dose was raised. It was then often necessary to induce the monkey to press the lever again by taping a raisin to the lever with cellulose tape. In an effort to extricate the raisin, the monkey activated the injector. If the monkey did not continue to self-administer nicotine at the higher dose level, the "priming" procedure of automatic hourly injections was repeated.

\section{Results}

Seven monkeys were tested at initial single intravenous doses of $10 \mu \mathrm{g} / \mathrm{kg}$ of nicotine. None of these monkeys initiated self-administration at this dose, even after a two-month period of automatic hourly injections.

The single dose was then raised to $25 \mu \mathrm{g} / \mathrm{kg}$ and at this level two of the seven monkeys began to self-administer nicotine spontaneously. After periods of priming ranging from two to ten days, each of the other five monkeys began to self-administer supplementary doses between the scheduled hourly injections. When the self-administration began, the automatic injections were discontinued and all 5 monkeys continued to self administer the drug. With individual doses of $25 \mu \mathrm{g} / \mathrm{kg}$, the average total daily doses ranged from 0.7 to $1.7 \mathrm{mg} / \mathrm{kg}$ among the various monkeys. The daily dose for each monkey was highly variable - changing as much as $100 \%$ on consecutive days. Although the self-administration patterns did not vary in a perfect pattern, all monkeys tended to take a large dose one day, followed by a small dose on the succeeding day.

At intervals of approximately one month, the individual doses were raised to $50,100,200,500,1000$, and finally $2000 \mu \mathrm{g} / \mathrm{kg}$. With each increment in dosage, all monkeys took fewer doses per day than at smaller doses, but the total daily dose increased until a step was reached at which a given monkey abruptly refused to self-administer the next higher dose.

One monkey died accidentally at the $25 \mu \mathrm{g} / \mathrm{kg}$ dose level. Of the six survivors, one refused to self-administer the $50 \mu \mathrm{g} / \mathrm{kg} /$ dose, two stopped at 100 $\mu \mathrm{g} / \mathrm{kg}$ and one each at 500 and $1000 \mu \mathrm{g} / \mathrm{kg}$. Only one monkey continued to self-administer nicotine at the $2.0 \mathrm{mg} / \mathrm{kg}$ level. At this dose, the maximum daily intake was $14.0 \mathrm{mg} / \mathrm{kg}$, and the average daily intake was $9.6 \mathrm{mg} / \mathrm{kg}$.

Objective physical signs following injection of nicotine were not observed at doses up to $100 \mu \mathrm{g} / \mathrm{kg}$. Doses of $200 \mu \mathrm{g} / \mathrm{kg}$ through $2.0 \mathrm{mg} / \mathrm{kg}$ produced signs of increasing severity which included yawning, piloerection, flushing followed by pallor, mydriasis followed by miosis, dyspnea, retching, vomiting, 
and muscular weakness to the point of prostration. Even at doses of 1.0 and $2.0 \mathrm{mg} / \mathrm{kg}$, the major signs of drug effect persisted only for periods of 5 to 10 minutes, and all signs disappeared after 20 minutes.

During the course of the study, the monkeys rarely self-administered nicotine during the hours of midnight to 8:00 a.m. when the laboratory lights were out. There was no evidence of an increased frequency of dosing either in the morning or late in the evening.

\section{Discussion}

It is clear that, under certain circumstances, monkeys will self-administer nicotine intravenously. These circumstances, involving individual housing and restraint of the animals, in no way resemble the natural habitat of monkeys. Nor does the intravenous route of administration of nicotine resemble closely the manner in which man self-administers this drug. However, the fact that monkeys will self-administer nicotine at all suggests that this alkaloid may be one of the substances in tobacco smoke which is responsible for man's use of tobacco. Experiments similar to those described above should be conducted with other pharmacologically active substances contained in tobacco smoke before any definite conclusions can be drawn. Other routes of self-administration by experimental animals should also be tested before any conclusions can be drawn concerning the relationship of self-administration of nicotine by animals and smoking of tobacco by man.

\section{Reference}

YANAGITA, T., G. A. DENEAU \& M. H. SEEVERS. 1965. Evaluation of pharmacologic agents in the monkey by long term intravenous self or programmed administration. Excerpta Medica International Congress Series 87: 453-457. 